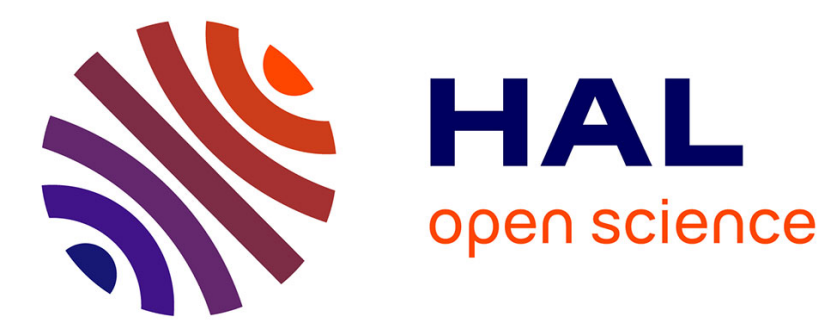

\title{
Dielectric spectroscopy as a probe for dynamic properties of compacted smectites
}

Agathe Cadène, Benjamin Rotenberg, S. Durand-Vidal, P. Turq, J.-C. Badot

\section{To cite this version:}

Agathe Cadène, Benjamin Rotenberg, S. Durand-Vidal, P. Turq, J.-C. Badot. Dielectric spectroscopy as a probe for dynamic properties of compacted smectites. Physics and Chemistry of The Earth, 2006, 31, pp.505-510. 10.1016/j.pce.2006.04.002 . hal-00123538

\section{HAL Id: hal-00123538 https://hal.science/hal-00123538}

Submitted on 9 Nov 2018

HAL is a multi-disciplinary open access archive for the deposit and dissemination of scientific research documents, whether they are published or not. The documents may come from teaching and research institutions in France or abroad, or from public or private research centers.
L'archive ouverte pluridisciplinaire HAL, est destinée au dépôt et à la diffusion de documents scientifiques de niveau recherche, publiés ou non, émanant des établissements d'enseignement et de recherche français ou étrangers, des laboratoires publics ou privés. 


\title{
Dielectric Spectroscopy as a probe for dynamic properties of compacted smectites
}

\author{
A. Cadène ${ }^{1}$, B. Rotenberg ${ }^{1}$, S. Durand-Vidal ${ }^{1}$, J.-C. Badot ${ }^{2}$ and P. Turq ${ }^{1}$ \\ ${ }^{1}$ Laboratoire Liquides Ioniques et Interfaces Chargées (UMR CNRS 7612), \\ Université P. et M. Curie, 4 place Jussieu, 75252 Paris Cedex 05, France \\ ${ }^{2}$ Laboratoire de Chimie Appliquée de l'Etat Solide (UMR CNRS 7574), \\ ENSCP, 11 rue P. et M. Curie, 75231 Paris Cedex 05, France
}

\begin{abstract}
The micro-dynamics of water and ions in two types of clays (montmorillonite and hectorite) was investigated with Broadband Dielectric Spectroscopy $(40 \mathrm{~Hz}$ to $5 \mathrm{GHz}$ ). Four to five relaxations were observed depending on the relative humidity, the clay type and the nature of the compensating counter-ion $\left(\mathrm{Na}^{+}\right.$or $\left.\mathrm{Cs}^{+}\right)$. A tentative assignment of the relaxations to physical mechanisms is proposed.
\end{abstract}

keywords: smectite clay, ion, transport, dielectric spectroscopy

\section{Introduction}

Clay minerals, particularly montmorillonite, are considered as possible materials for waste storage, including the radioactive ions from the nuclear waste. The performance of the confinement critically depends on the transport properties of the ions inside the material. These properties are very sensitive to the hydration state of the clay, which is very low in the particular case (dry compacted clay). We used Broadband Dielectric Spectroscopy (BDS) in order to access the characteristic relaxation times related to ionic translation (individual or collective), and to dipolar rotation of water molecules. After presenting the systems and experimental procedures used in this study (section I), we will discuss the assignment of each relaxation frequency to 
particular physical mechanisms. To achieve this assignment, we used two types of clays and two compensating counter-ions (no added salt), at two relative humidities (section II). Complementary informations were obtained through non-equilibrium measurements on a sample during drying (section III). The assignment of the relaxations is presented in section IV, and a conclusion is given.

\section{Materials and Methods}

Natural montmorillonite was obtained by purification of commercial bentonite MX-80. The size fraction $<2 \mu \mathrm{m}$ was prepared by dispersion of $40 \mathrm{~g}$ of bentonite in $1 \mathrm{~L}$ of deionized water, followed by centrifugation at appropriate velocities in order to remove mineralogical impurities and redispersed in $\mathrm{pH} 5$ water at $80^{\circ} \mathrm{C}$ under stirring for $12 \mathrm{~h}$. Na saturation of the montmorillonite suspension was carried out by dispersing the sediment in $\mathrm{NaCl} 10^{-1}$ mol. $\mathrm{L}^{-1}$ solution, stirring for $12 \mathrm{~h}$ (repeated twice), and repeated washing with deionized water until complete removal of chloride anions is achieved $\left(\mathrm{AgNO}_{3}\right.$ test). Cs exchanged montmorillonite was obtained by reproducing the last steps, starting from the $\mathrm{Na}$ saturated clay, with $\mathrm{CsCl}$ instead of $\mathrm{NaCl}$. Since no anions are present, no cations other than that balancing the structural charge of the clay sheets can be found in the sample. The resulting sample was then dried at $80^{\circ} \mathrm{C}$ for three days and crushed. The powder was then stored under dry atmosphere. The structure of the resulting material is (Sauzeat 2001): $\left(\mathrm{Si}_{7.96} \mathrm{Al}_{0.04}\right)\left(\mathrm{Al}_{3.1} \mathrm{Mg}_{0.56} \mathrm{Fe}^{\mathrm{III}}{ }_{0.18} \mathrm{Fe}^{\mathrm{II}}{ }_{0.16}\right) \mathrm{O}_{20}(\mathrm{OH})_{4} \mathrm{M}_{0.76}$ (with $\mathrm{M}=\mathrm{Na}$ or $\mathrm{Cs}$ ). The quality of purification was controlled by X-ray diffraction. Synthetic fluorohectorite was kindly provided by J. Breu, Inorganic Chemistry Laboratory, Bayreuth University, Germany. The structure of these clays is $\mathrm{Si}_{8}\left(\mathrm{Mg}_{5.2} \mathrm{Li}_{0.8}\right) \mathrm{O}_{20} \mathrm{~F}_{4} \mathrm{Na}_{0.8}$ and their charge density is very close to that of natural montmorillonite (Breu 2003). The great advantage of such synthetic clays is that their charge density is very homogeneous. This results in a much better defined overall structure, especially upon hydration.

Starting with a dry sample is a crucial point, since the high complexity of the smectite hydration mechanism 
renders the reproducibility of the hydration step rather difficult. Indeed, the final state depends not only on the applied relative humidity $(\mathrm{RH})$, but also on the initial hydration state. Berend showed that starting from the dry state (roughly one water molecule per cation), equilibration with an atmosphere of $43 \% \mathrm{RH}$ and $85 \% \mathrm{RH}$ leads mainly to a water monolayer and bilayer respectively (Berend 1991, Cases 1992). Dry samples were therefore introduced for 2 weeks in a closed chamber with a given $\mathrm{RH}$, obtained by equilibration over a saturated solution $\left(\mathrm{K}_{2} \mathrm{CO}_{3}\right.$ for $43 \%$ and $\mathrm{KCl}$ for $\left.85 \%\right)$. The amounts of water adsorbed by the samples were controlled by measuring the weight uptake. Results are summarized in table 1.

The samples were then compacted to pellets with a diameter of $3 \mathrm{~mm}$ and a thickness of $1 \mathrm{~mm}$, under a pressure of 700MPa. Electrical contact with the measurement cell was achieved by the presence of a thin layer of silver paint on each side of the sample; the solvent evaporates almost instantaneously, leaving a film of silver clusters

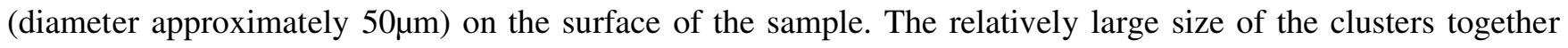
with the high evaporation rate of the solvent prevent the sample from contamination by the silver. The same cell was used for both low and high frequency measurements. The study of real and imaginary parts of the complex dielectric permittivity was performed in the frequency range of $40 \mathrm{~Hz}$ to $5 \mathrm{GHz}$ with two different automatic devices (Badot 1992):

- $40 \mathrm{~Hz}$ to 110MHz: LF impedance analyzer model Hewlett Packard HP4294A

- 45MHz to 5GHz: RF impedance analyzer model Hewlett Packard HP8510

The raw data were subsequently analyzed using an inhouse code. Deconvolution of the Argand and Bode diagrams leads to the number of relaxations and to the characteristic time and amplitude of each process. As an illustration of the deconvolution process, figure 1 shows the Argand diagram obtained with the Na-hectorite sample equilibrated at $43 \% \mathrm{RH}$. In 1a, the whole diagram is shown, but only the slowest relaxation (R1) is visible, because of its much larger amplitude (compared to the others, see table 3). In order to distinguish the 
other relaxations, one needs to proceed to the deconvolution of R1, using the Cole-Cole form of dielectric relaxation function (Badot 1992). The four faster relaxations are represented in 1b, together with the corresponding angular frequencies and the deconvoluted signal corresponding to each remaining relaxations (R2, R3, R4 and R5). Note the difference in scale between 1a and 1b. Although it is not obvious from figure 1a because of the scale used here, the line is a portion of circle.

\section{Equilibrium Measurements}

\section{1) Relative Humidity}

Figure 2 shows the evolution of the conductivity with frequency, for $\mathrm{Na}$ montmorillonite (MNa) at two relative humidities (43\% and $85 \% \mathrm{RH})$ and for Cs montmorillonite (MCs) at $85 \% \mathrm{RH}$. Figure 2 reveals that conductivity increases with water content. The low-frequency $(100 \mathrm{~Hz})$ conductivity is enhanced by two orders of magnitude, while at higher frequencies $(\mathrm{GHz})$ the magnification factor is much smaller (approximately 2 to 10 ). This also holds for $\mathrm{Na}$ hectorite $(\mathrm{HNa})$.

More insight on the relation between water content and conductivity can be obtained by analyzing the frequency dependent permittivity (related to the complex conductivity through the relation $\sigma^{*}(\omega)=\sigma_{0}+\mathrm{i} \omega \varepsilon^{*}(\omega)$ - where $\mathrm{w}$ is the angular frequency) as explained in the previous section. For montmorillonite, the deconvolution process results in 5 distinct relaxations (labeled R1 to R5) whose characteristics are summarized in table 2. The results for hectorite with a similar charge density, summarized in table 3 , show that for this solid only 4 relaxations are observed at $85 \% \mathrm{RH}$.

Although it is difficult at this stage to assign each relaxation to a particular mechanism, we can make a tentative correlation between the water content and the number of observed relaxations. Indeed, structural studies (Cadène 2005) have shown that the interlayers of $\mathrm{HNa}$ at $43 \% \mathrm{RH}$ consist exclusively of water monolayers, whereas only bilayers are present at $85 \%$. Montmorillonite however is characterized by a high degree of inter- 
stratification, that is the simultaneous presence of mono and bilayers at 85\% RH (Ferrage 2005). Therefore, we suggest that the five distinct relaxations are associated to the presence of water monolayers between the clay sheets (43\% RH), while only four distinct relaxations are observed when water bilayers only are present (85\% RH). We will discuss below the possible mechanisms for the relaxations, and try to explain the disappearance of one of them when going from mono to bilayer.

\section{2) Counter-ion}

Figure 2 shows that at $85 \% \mathrm{RH}, \mathrm{Cs}$ montmorillonite is less conducting than its $\mathrm{Na}$ counterpart. This result also holds at $43 \%$ RH. Table 2 shows the influence of the counter-ion on the observed relaxations. For montmorillonite at $85 \% \mathrm{RH}$, results obtained with $\mathrm{Na}^{+}$and $\mathrm{Cs}^{+}$counter-ions are shown. Only monolayers are present with $\mathrm{Cs}^{+}$, even at high $\mathrm{RH}$. This is because the driving force for the crystalline swelling is the hydration of the counter-ion, and cesium is not hydrophilic enough to induce the introduction of a second water layer between the clay sheets. Although it is known from molecular dynamics simulations and neutron diffusion experiments that the diffusion mechanism of $\mathrm{Cs}^{+}$is very different from that of $\mathrm{Na}^{+}$(Malikova 2005), there could be an indirect influence of the nature of the compensating counter-ion on the conductivity, namely the equilibrium water content that it induces. As shown in figure 2, the conductivity of MCs at $85 \% \mathrm{RH}$ is comparable to that of $\mathrm{MNa}$ at $43 \% \mathrm{RH}$, and both samples correspond to water monolayers.

\section{3) Clay type}

The influence of the clay type on the conductivity can be investigated by comparing the conductivity of montmorillonite and hectorite with the same counter-ion $\left(\mathrm{Na}^{+}\right)$. As for montmorillonite, the conductivity of $\mathrm{Na}$ hectorite increases with water content, and there is a clear correlation between water content and conductivity: at $43 \% \mathrm{RH} \mathrm{HNa}$ is slightly more conducting than $\mathrm{MNa}$, while at $85 \% \mathrm{RH}$ the conductivity of $\mathrm{MNa}$ is greater 
than that of $\mathrm{HNa}$ (result not shown). Since water uptake measurements have shown that under an atmosphere with $43 \% \mathrm{RH}$, the water content of Na montmorillonite is slightly lower than that of Na hectorite with a similar charge density, while at $85 \% \mathrm{RH}$ montmorillonite contains more water (table 1), we conclude that the clay type only affects the conductivity through its equilibrium water content, which in turn determines the conductivity.

When the water content increases, the evolution of the first relaxation (R1) is the same for both montmorillonite and hectorite with Na counter-ion: its amplitude increases considerably, while its frequency hardly changes (see tables 2 and 3). The three following relaxations (R2, R3 and R4) show the opposite trend (both for montmorillonite and hectorite): their frequency increases by an average factor of 7 , while their magnitude does not vary significantly (with the exception of $\mathrm{R} 2$ in hectorite). The uncertainties on the characteristics of the last relaxation (R5) are relatively high, for several reasons. First, from the principle of the deconvolution process, each relaxation is observed after "substracting" the contribution of the one occurring at lower frequencies (deconvolution). Therefore any inaccuracy affecting the latter will be transferred to the former. Second, the accessible frequency range covers only part of the frequency range associated to R5: our devices cannot produce signals beyond $5 \mathrm{GHz}$, and this shows that the frequency of R5 is larger than that (high) value. Nevertheless, this is enough to claim that R5 is likely to be related to the rotation of (polar) water molecules (see section IV).

\section{Non-Equilibrium Measurements on a drying sample}

The link between the precise location of water and dielectric properties was further investigated by reproducing the previous experiments while drying a sample. A Na hectorite sample equilibrated at $85 \% \mathrm{RH}$ was heated to $60{ }^{\circ} \mathrm{C}$, and its dielectric response over the whole frequency range was measured at various times: first every 10 minutes, until 40 minutes after the beginning of the experiment, then every 30 minutes. The initial time $t_{0}$ was taken to be 5 minutes after introduction of the sample in the measurement cell; the state of the sample at $t_{0}$ is probably not that of the equilibrated sample, because in 5 minutes some water may have already evaporated. 
The purpose of such a study is to follow the effect of water release on each relaxation. By maintaining a constant temperature, we discard any influence of the possible activation energies associated to the conduction mechanisms.

As expected from the equilibrium measurements (Section II), the conductivity decreases with time, that is with decreasing water content (see figure 3). The last curve is close to that obtained with a sample equilibrated at $43 \% \mathrm{RH}$ and at $60^{\circ} \mathrm{C}$, also represented on this figure. However, the decrease in the low-frequency conductivity $\left(<10^{5} \mathrm{~Hz}\right)$ is already significant from the early stages of dehydration, while the high-frequency conductivity $(>$ $10^{8} \mathrm{~Hz}$ ) appears to occur only after some time $\left(\mathrm{t}_{0}+40 \mathrm{~min}\right)$. This trend is confirmed by the study of the characteristic frequencies and amplitudes as a function of time, summarized in table 4. This table also shows that only four relaxations are observed until $t_{0}+40$, but five distinct relaxations are seen for later stages of dehydration. As was mentioned in section II, four relaxations correspond to water bilayers, and a fifth is observed when monolayers are present. Thus the present experiment speaks in favor of a two steps dehydration process: first the porewater from general pores leaves the sample, then the interstitial water is evaporated (bi- to monolayer).

\section{IV.Relaxation Mechanisms}

Each relaxation corresponds to a particular microscopic mechanism. Possible mechanisms include (see figure 4): (i) reorientation of polar molecules (like water), (ii) formation of induced dipoles by displacements of charge carriers (like ions). In the former case, the characteristic frequency will depend mainly on the environment of the molecules, and the amplitude on the number of molecules with a given environment. In the latter case, the motion of charge carriers can occur over various length scales, and the corresponding frequencies vary accordingly. We now want to discuss the possibility of assigning a mechanism to each observed relaxation. Relevant information can be obtained by studying: (i) the orders of magnitude of the frequencies, (i) the 
corresponding amplitudes, (iii) the variations with water content and with counter-ion.

The characteristic frequency of R5 is slightly lower than that of bulk water (18 GHz, see Buchner 1999) and independent of the sample. In confined materials like clays, the rotation of water molecules is hindered, so that its characteristic frequency is expected to be lower than for "free" water. At the other extreme, the magnitude and the low frequency of R1 suggest that it is related to "grain polarization", that is the formation of induced dipoles by the motion of counter-ions along the clay sheets, leading to charge separations at the hundreds of nanometers scale. Furthermore, the large increase of the magnitude with water content can be traced back to the greater mobility of cations in the interlayer at higher water content, and thus easier fluctuations of the charge density. The fact that the low-frequency conductivity decreases when the general porewater leaves the sample, while the high-frequency conductivity hardly decreases at that stage, is consistent with that microscopic interpretation of R1.

The assignment of the intermediate relaxations is more problematic. We have shown (Rotenberg 2005) that the frequency of R4 is consistent with charge fluctuations developing at the nanometer scale, that is the typical distance between ions in the interlayer (or equivalently, between the structural charges within the sheets). Indeed, that distance is roughly $0.8 \mathrm{~nm}$ in montmorillonite, and the diffusion coefficient of $\mathrm{Na}$ is approximately $510^{-11} \mathrm{~m}^{2} \mathrm{~s}^{-1}$ in a water monolayer, and one order of magnitude larger in a water bilayer (Marry 2002). Thus, the time it takes for an ion to diffuse to the next charged site is typically $\tau \sim \mathrm{L}^{2} / \mathrm{D}=10 \mathrm{~ns}$, or in terms of frequency $10^{8} \mathrm{~Hz}$, which is the correct order of magnitude. For more details, the reader can refer to (Rotenberg 2005).

Quasi-Elastic Neutron Scattering Experiments (QENS) have shown that there are in fact two types of water in the sample, with two distinct dynamics (Cadène 2005). These two types could be either (a) water in the interlayers and water in the pores, or (b) water solvating cations and water not belonging to the cation's solvation shell. If R5 corresponds to "free" water, then the other type of water should have a lower characteristic frequency. If in addition R4 is attributed to local ionic motion, then the relaxation corresponding to the "bound" 
water is either R2 or R3. An interesting feature of R3 is that it is not present in Na-hectorite at high water content. Furthermore it disappears upon drying of a highly hydrated sample (table 4). Given the precision of the measurements, we cannot tell whether the physical mechanism leading to R3 is not present in that case, or if it occurs at a higher frequency, making it difficult to distinguish from R4. Therefore it is difficult to give a definitive answer for R2 and R3. A possible mechanism for explaining the remaining relaxation is the ionic adsorption/desorption exchange at the clay surface. The consequences of such an exchange on the dielectric properties were discussed in (Rotenberg 2005), but we have not enough experimental evidences to conclude that it corresponds indeed to one of the observed relaxations.

\section{Conclusion}

Broadband Dielectric Spectroscopy was used to study the nano- and micro-dynamics of ions and water in clays at low water content. Mechanisms were suggested to interpret the observed dielectric relaxations, relying on results obtained by varying the clay type (montmorillonite and hectorite), the compensating counter-ion $\left(\mathrm{Na}^{+}\right.$ and $\mathrm{Cs}^{+}$) and the relative humidity. Complementary informations were obtained with non-equilibrium measurements on a drying sample. Quasi-Elastic Neutron Scattering and Molecular Dynamics simulation results from the literature were also used as a guide for interpreting the experimental results. We hope that more insight on the water dynamics will be gained from Nuclear Magnetic Resonance experiments, in order to verify the validity of the mechanisms proposed in this paper. Corresponding collaborations have been started.

\section{Acknowledgments}

The authors acknowledge financial support of Groupement de Recherches PARIS. B.R. acknowledges financial support of the Ecole Normale Supérieure de Paris (ENS) and the Agence Nationale pour la gestion des Déchets 
Radioactifs (ANDRA).

\section{References}

Badot JC, Baffier N, 1992. J. Mater. Chem. 2, 1167.

Bérend I, 1991. Les Mécanismes d'hydratation de montmorillonites homoioniques pour des pressions relatives inférieures à 0.95, Ph. D. thesis (in French), Institut National Polytechnique de Lorraine, France.

Cases JM, Bérend I, Besson G, Francois M, Uriot JP, Thomas F, Poirier JE, 1992. Langmuir 8, 2730.

Breu J, Seidl W, Stoll A, 2003. Zeit. Anorg. Allg. Chem. 629, 503.

Buchner R, Barthel J, Stauber J, 1999. Chem. Phys. Lett. 306, 57.

Cadène A, Etude expérimentale multi-échelle du transport ionique et aqueux en milieu poreux chargé: argiles, Ph. D. Thesis (in French), Université P. et M. Curie, Paris France (oct. 2005).

Ferrage E, Lanson B, Malikova N, Plançon A, Sakharov BA, Drits VA, 2005. Chem. Mater. 17, 3499.

Malikova N, Cadène A, Marry V, Dubois E, Turq P, Zanotti JM, Longeville S, 2005. Chem. Phys., in press.

Marry V, Turq P, Cartailler T, Levesque D, 2002. J. Chem. Phys. 117, 3454.

Rotenberg B, Cadène A, Dufrêche JF, Durand-Vidal S, Badot JC, Turq P, 2005. J. Phys. Chem. B, 109, 15548.

Sauzeat E, Guillaume D, Neaman A, Peiffert C, Ruck R, Dubessy J, Cathelineau M, Villiéras F, Yvon J, 2001. MX-80: Une référence méthodologique pour l'ANDRA, Note technique ANDRA (in French). 


\begin{tabular}{llc}
\hline & & $\mathrm{m}\left(\mathrm{g}_{\text {H20 }} / \mathrm{g}_{\text {dry clay }}\right)$ \\
\hline Montmorillonite & Na 43\% RH & 0.0458 \\
Montmorillonite & Na 85\% RH & 0.1656 \\
Montmorillonite & Cs 85\% RH & 0.1163 \\
Hectorite & Na 43\% RH & 0.0745 \\
Hectorite & Na 85\% RH & 0.1307 \\
\hline
\end{tabular}

Table 1: Amounts of absorbed water, starting from dry samples.

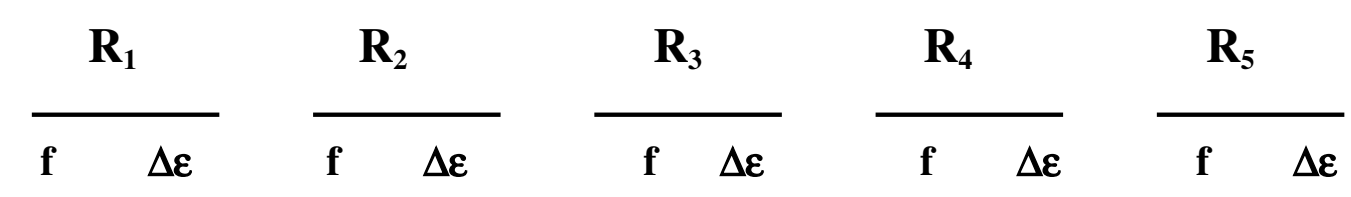

\begin{tabular}{|c|c|c|c|c|c|c|c|c|c|}
\hline $\mathrm{Na} 43 \%$ & $1.6 \mathrm{E} 3$ & $5.9 \mathrm{E} 4$ & $1.4 \mathrm{E} 6$ & $4.9 \mathrm{E} 1$ & $1.4 \mathrm{E} 7$ & $2.6 \mathrm{E} 1$ & $2.1 \mathrm{E} 8$ & $1.0 \mathrm{E} 1$ & $1.5 \mathrm{E} 10 \quad 4.9 \mathrm{E} 0$ \\
\hline Na $85 \%$ & $1.5 \mathrm{E} 3$ & $1.4 \mathrm{E} 6$ & $7.2 \mathrm{E} 6$ & $6.6 \mathrm{E} 1$ & $8.5 \mathrm{E} 7$ & $2.6 \mathrm{E} 1$ & $3.6 \mathrm{E} 8$ & $1.4 \mathrm{E} 1$ & 8.9E9 4.3E0 \\
\hline Cs $85 \%$ & $2.9 \mathrm{E} 3$ & $8.6 \mathrm{E} 4$ & $1.7 \mathrm{E} 6$ & $3.1 \mathrm{E} 1$ & $1.6 \mathrm{E} 7$ & $1.1 \mathrm{E} 1$ & $1.5 \mathrm{E} 8$ & $3.6 \mathrm{E} 0$ & $4.0 \mathrm{E} 10 \quad 5.0 \mathrm{E} 0$ \\
\hline
\end{tabular}

Table 2: Relaxation frequencies and amplitudes for montmorillonite, with varying relative humidity and counter-ion. Frequencies (f) are in $\mathrm{Hz}$, and amplitudes $(\Delta \varepsilon)$ are dimensionless.

\begin{tabular}{|c|c|c|c|c|c|c|c|c|c|}
\hline \multicolumn{2}{|c|}{$\mathbf{R}_{1}$} & \multicolumn{2}{|c|}{$\mathbf{R}_{2}$} & \multicolumn{2}{|c|}{$\mathbf{R}_{\mathbf{3}}$} & \multicolumn{2}{|c|}{$\mathbf{R}_{4}$} & \multicolumn{2}{|c|}{$\mathbf{R}_{5}$} \\
\hline $\mathbf{f}$ & $\Delta \varepsilon$ & $\mathbf{f}$ & $\Delta \varepsilon$ & f & $\Delta \varepsilon$ & f & $\Delta \varepsilon$ & $\mathbf{f}$ & $\Delta \varepsilon$ \\
\hline $.4 \mathrm{E} 3$ & $3.3 \mathrm{E} 4$ & 6.6E6 & $3.4 \mathrm{E} 1$ & 5.3E7 & $1.6 \mathrm{E} 1$ & $3.2 \mathrm{E} 8$ & $5.5 \mathrm{E} 0$ & $3.2 \mathrm{E} 9$ & $1.3 \mathrm{E} 0$ \\
\hline $.0 \mathrm{E} 3$ & $2.8 \mathrm{E} 6$ & $1.7 \mathrm{E} 7$ & $3.4 \mathrm{E} 1$ & - & - & $2.8 \mathrm{E} 8$ & $1.1 \mathrm{E} 1$ & $3.9 \mathrm{E} 9$ & $1.3 \mathrm{E} 0$ \\
\hline
\end{tabular}

Table 3: Relaxation frequencies and amplitudes for hectorite, with varying relative humidity. Frequencies (f) are in $\mathrm{Hz}$, and amplitudes $(\Delta \varepsilon)$ are dimensionless. 


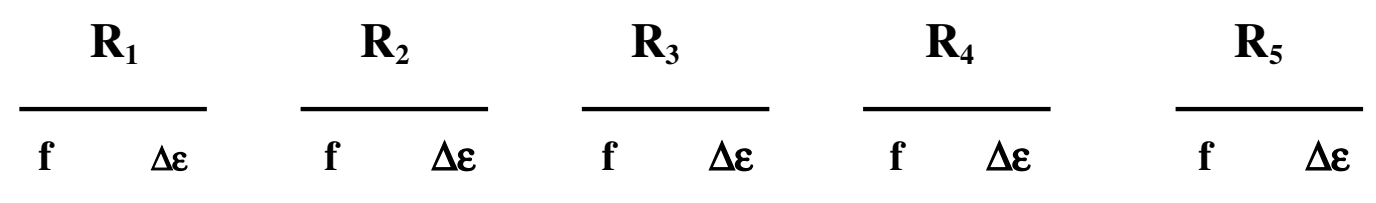

\begin{tabular}{lllllllllll}
\hline $\mathbf{t 0}$ & $2.4 \mathrm{E} 4$ & $6.3 \mathrm{E} 4$ & $4.6 \mathrm{E} 7$ & $3.1 \mathrm{E} 1$ & - & - & $5.2 \mathrm{E} 8$ & $7.2 \mathrm{E} 0$ & $2.8 \mathrm{E} 9$ & $1.3 \mathrm{E} 0$ \\
$\mathbf{t}+\mathbf{1 0}$ & $4.4 \mathrm{E} 4$ & $4.2 \mathrm{E} 4$ & $5.3 \mathrm{E} 7$ & $3.4 \mathrm{E} 1$ & - & - & $7.7 \mathrm{E} 8$ & $6.1 \mathrm{E} 0$ & $5.3 \mathrm{E} 9$ & $6.0 \mathrm{E}-1$ \\
$\mathbf{t + 2 0}$ & $2.8 \mathrm{E} 4$ & $4.5 \mathrm{E} 4$ & $5.6 \mathrm{E} 7$ & $3.2 \mathrm{E} 1$ & - & - & $7.1 \mathrm{E} 8$ & $4.7 \mathrm{E} 0$ & $2.9 \mathrm{E} 9$ & $5.9 \mathrm{E} 0$ \\
$\mathbf{t}+\mathbf{3 0}$ & $2.6 \mathrm{E} 4$ & $4.1 \mathrm{E} 4$ & $5.1 \mathrm{E} 7$ & $2.9 \mathrm{E} 1$ & - & - & $5.8 \mathrm{E} 8$ & $5.9 \mathrm{E} 0$ & $3.9 \mathrm{E} 9$ & $4.9 \mathrm{E} 0$ \\
$\mathbf{t}+\mathbf{4 0}$ & $2.2 \mathrm{E} 4$ & $4.2 \mathrm{E} 4$ & $6.4 \mathrm{E} 7$ & $3.0 \mathrm{E} 1$ & - & - & $8.2 \mathrm{E} 8$ & $3.6 \mathrm{E} 0$ & $6.7 \mathrm{E} 9$ & $6.1 \mathrm{E} 0$ \\
$\mathbf{t}+\mathbf{7 0}$ & $1.6 \mathrm{E} 4$ & $4.5 \mathrm{E} 4$ & $2.4 \mathrm{E} 7$ & $4.1 \mathrm{E} 1$ & $2.1 \mathrm{E} 8$ & $4.3 \mathrm{E} 0$ & $2.8 \mathrm{E} 8$ & $1.1 \mathrm{E} 1$ & $3.0 \mathrm{E} 9$ & $1.4 \mathrm{E} 0$ \\
$\mathbf{t}+\mathbf{1 0 0}$ & $1.2 \mathrm{E} 4$ & $4.4 \mathrm{E} 4$ & $2.2 \mathrm{E} 7$ & $2.8 \mathrm{E} 1$ & $1.9 \mathrm{E} 8$ & $2.7 \mathrm{E} 0$ & $2.8 \mathrm{E} 8$ & $1.1 \mathrm{E} 1$ & $4.5 \mathrm{E} 9$ & $1.5 \mathrm{E} 0$ \\
$\mathbf{t + 1 3 0}$ & $8.0 \mathrm{E} 3$ & $4.1 \mathrm{E} 4$ & $1.6 \mathrm{E} 7$ & $3.9 \mathrm{E} 1$ & $1.6 \mathrm{E} 8$ & $3.0 \mathrm{E} 0$ & $2.5 \mathrm{E} 8$ & $1.0 \mathrm{E} 1$ & $2.5 \mathrm{E} 9$ & $6.2 \mathrm{E}-1$ \\
\hline
\end{tabular}

Table 4: Relaxation frequencies and amplitudes for a dehydrating $\mathrm{Na}$ hectorite, at various times (see text).

Frequencies (f) are in $\mathrm{Hz}$, and amplitudes $(\Delta \varepsilon)$ are dimensionless. Note that a fifth relaxation appears after $\mathrm{t}+70$.

\section{Captions}


Figure 1: Argand plot (imaginary part vs. real part of the complex permittivity) for Na-hectorite at $43 \%$ relative humidity: (a) on the whole experimental curve, only one relaxation (R1) is visible; (b) substraction of its contribution reveals the four remaining relaxations (note the difference in scale). Crosses denote the experimental data, and the continuous lines the contribution of each relaxation. The characteristic frequencies are also indicated (in $\mathrm{Hz})$.

Figure 2: Frequency-dependent conductivity for montmorillonite with varying relative humidity and counterion.

Figure 3: Frequency-dependent conductivity for a drying sample of Na-hectorite at $60^{\circ} \mathrm{C}$.

Figure 4: Schematic view of the proposed relaxation mechanisms. At the highest frequencies (R5), dipolar reorientation of water molecules (a). At the lowest frequencies (R1), polarization of the grain by ionic density inhomogeneity over hundreds of nanometers (d). At intermediate frequencies (R2 to R4), possible mechanisms include local ionic motion along the surfaces (b) -the jump length scale is the nanometer- and reorientation of "bound" water molecules (c); for the latter case, one can think of water bound either to a cation, or to the mineral surfaces (not represented here). 

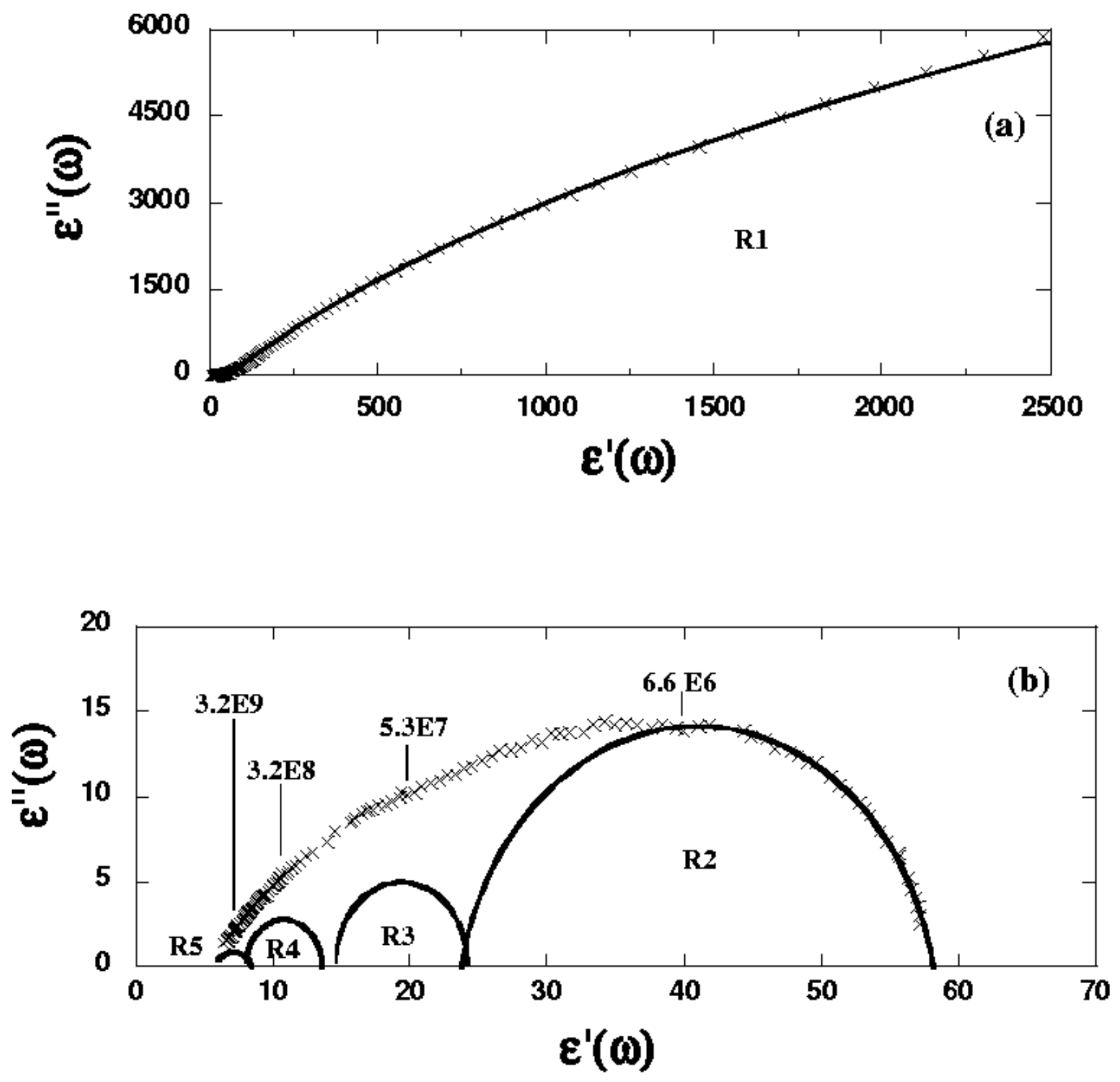

Figure 1 


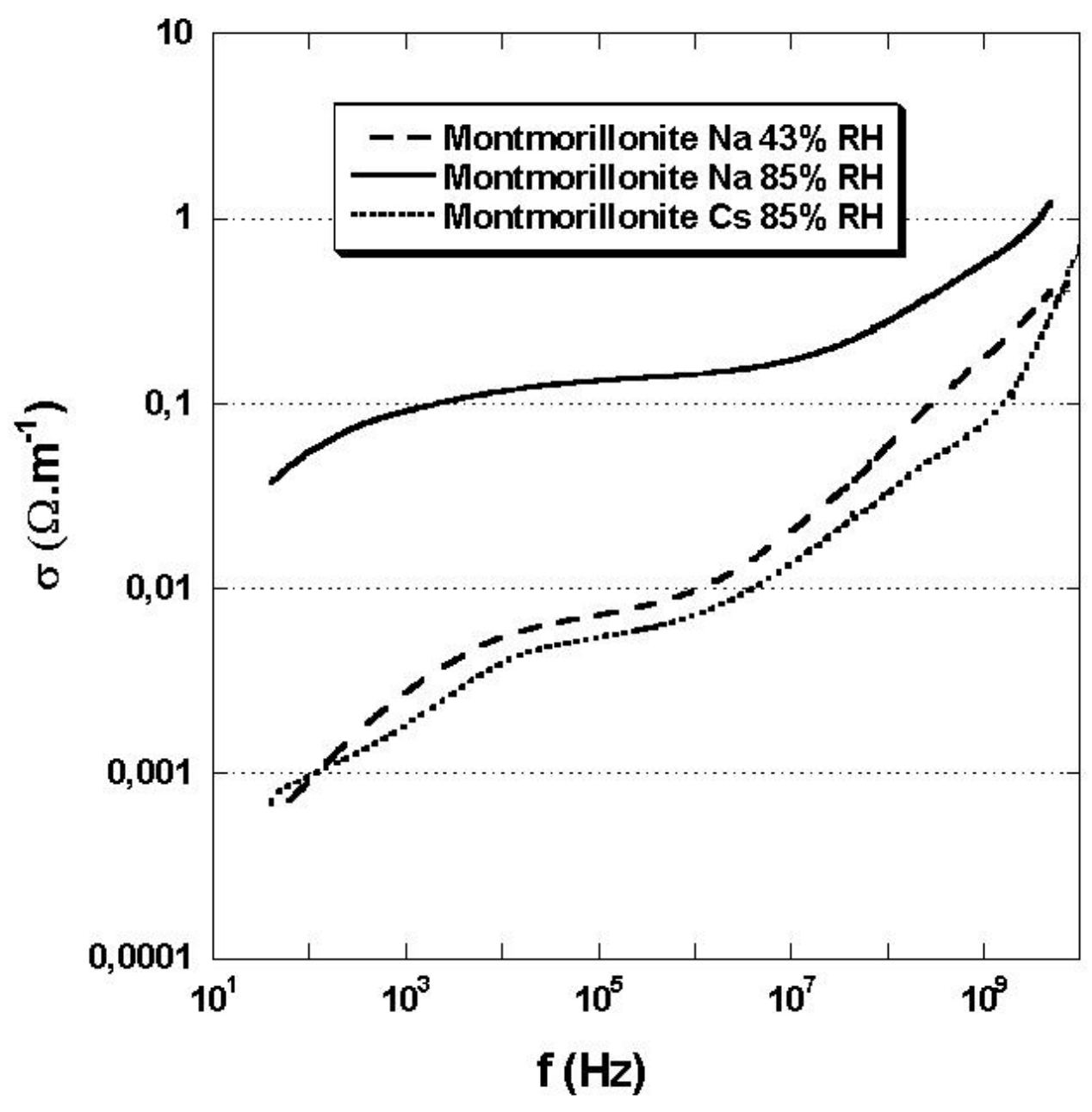

Figure 2 


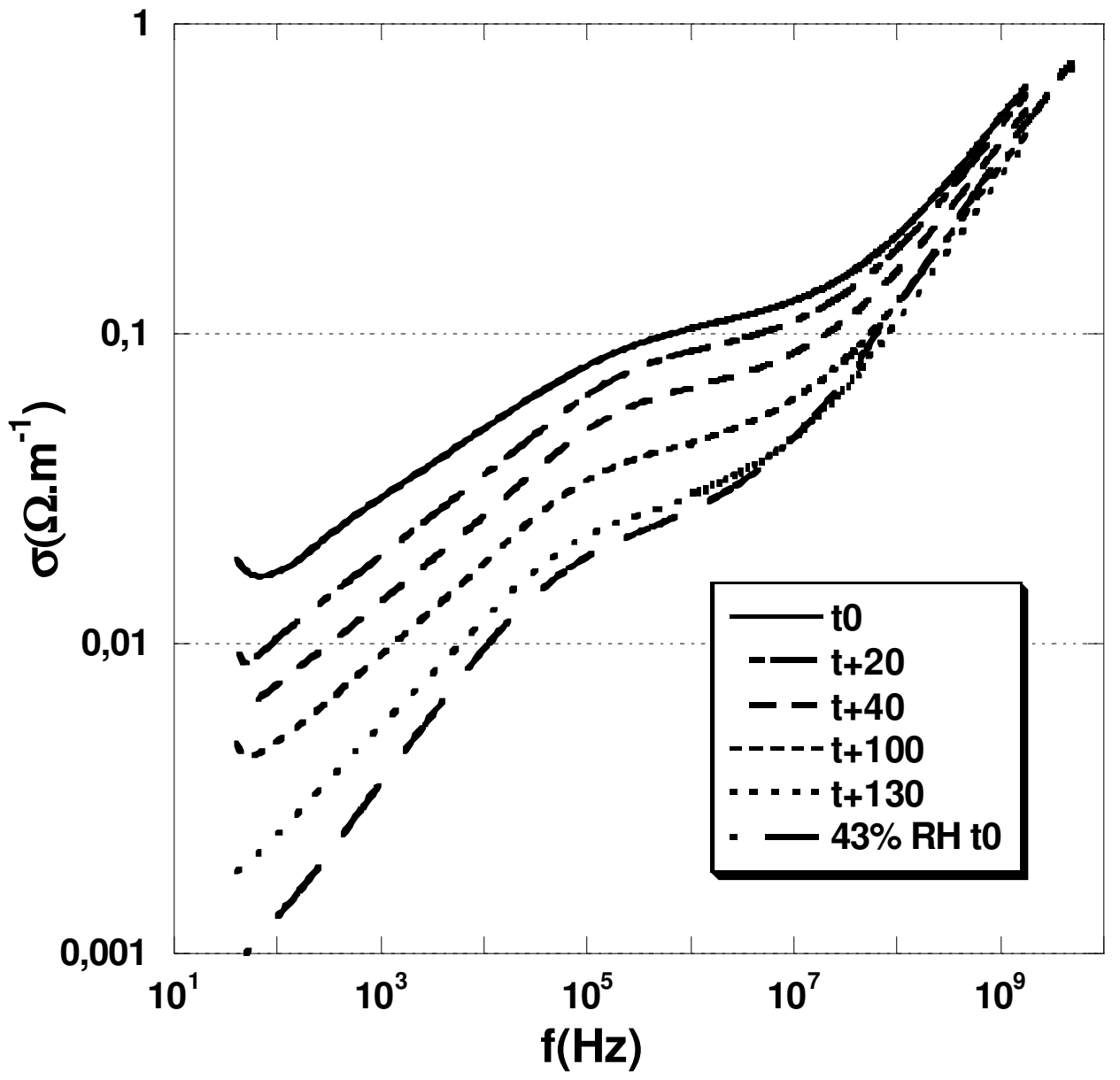

Figure 3 


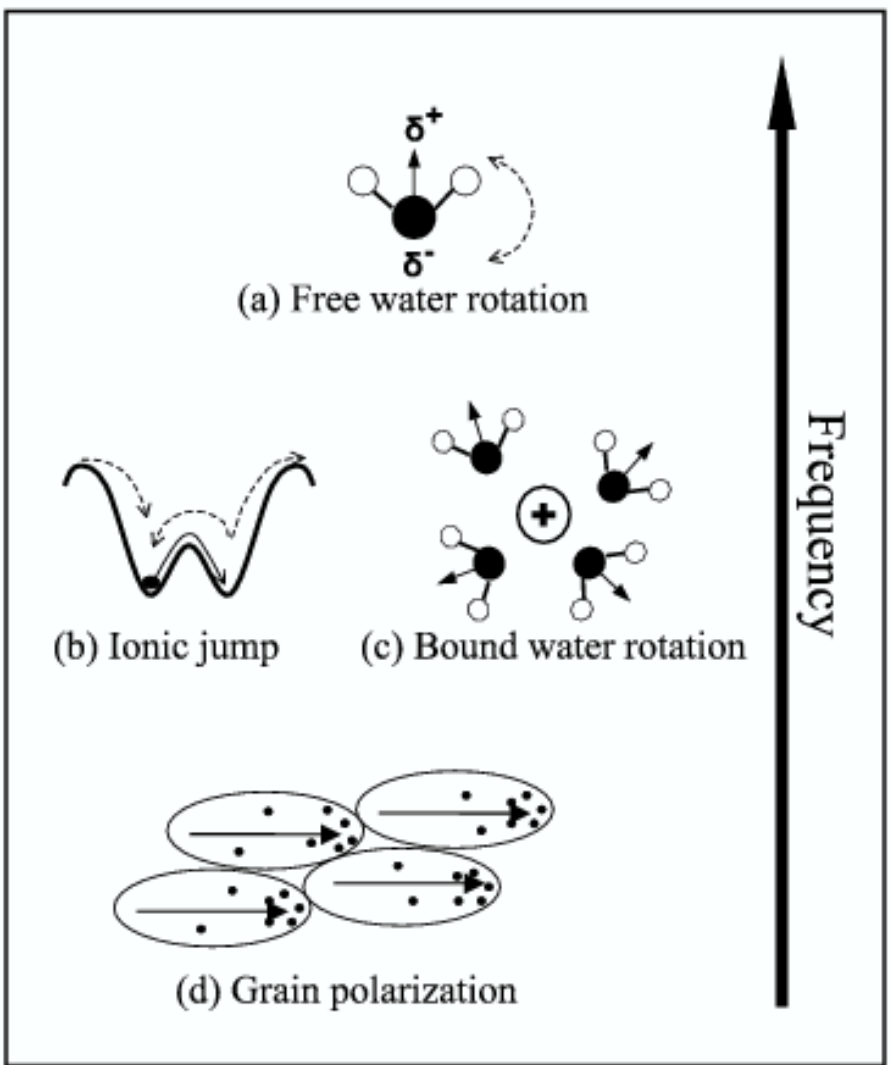

Figure 4 